\title{
Linguistic Representation of Professional Values in Popular Science Discourse of IT: Axiological and Pragmatic Perspective
}

\author{
Tatiana Aleksandrovna Shiryaeva ${ }^{1}$, Alexander Yurievich Bagiyan², Amaliya Robertovna Arakelova ${ }^{3 *}$ \\ ${ }^{1}$ Professor, Doctor of Philology, Head of the Chair of English Language and Professional Communication, Pyatigorsk State University \\ ${ }^{2}$ Associate Professor, PhD, the Chair of Theoretical Linguistics and Practice of Cross-Cultural Communication, Pyatigorsk State \\ University \\ ${ }^{3} \mathrm{PhD}$, The Chair of English Language and Professional Communication, Pyatigorsk State University
}

Corresponding Author: Amaliya Robertovna Arakelova, E-mail: amaliia.arakelova@gmail.com

\section{ARTICLE INFO}

\section{Article history}

Received: July 14, 2018

Accepted: September 06, 2018

Published: December 01, 2018

Volume: 7 Issue: 7

Advance access: October 2018

Special Issue on Language \&

Literature

Conflicts of interest: None

Funding: Yes

\begin{abstract}
The article examines how professional values acquire linguistic form and spread via the modern discourse of Information Technology. As an extremely dynamic sphere of human activity, the industry of information technology reflects the processes that take place in the society and influence the way people interact, share information, process data and implement knowledge. As a result, the language that is employed for describing, informing, reporting and promoting IT products and ideas inevitably reflects the most important concepts that are typical of this sphere, i.e., values. The article explores the way the discourse of IT is shaped and linguistically conditioned by a certain professional value system and its features. This is the area that has not been thoroughly explored from the standpoint of linguistics, but which, however, requires substantial research due to apparent societal and scientific relevance. The study of popular science discourse as presented in the biggest technology magazines revealed that values determine the language means, modality of the texts, communication aims, all of which are set by the addresser. Moreover, when viewed from the perspective of linguistics, values are found to depend on the language both for the cognitive and pragmatic purposes. Identification and interpretation of the most prominent values of the popular science discourse of IT is aimed to bridge socio-cognitive, linguistic and pragmatic aspects of these entities: an interdisciplinary study that has not been conducted before.
\end{abstract}

Key words: Axiological Linguistics, Discourse Analysis, Values, Discourse Of Information Technology, Information Technology (IT), Popular Science Discourse

\section{INTRODUCTION}

Throughout the history, profession-related activities have been going through constant changes, both in terms of quality and quantity, as well as in structure and content. However, the rapid development of computer technologies that has taken place in the XXI century leaves people little choice but to admit the existence of completely new, special ways of cognition that are typical of modern people regardless of their profession. Multiple forms and functions of products generated by the digital industry together with the transforming potential that these products have, serve as motivation for substantial scientific research. Ubiquitous computerization phenomenon and the communication it entails for the purposes of creation, dissemination and exploitation of technologies are now subject to close scientific scrutiny, including that of linguistics.
Current linguistic studies concentrate on a wide range of aspects: from investigating communication facilitated by computer technologies (e.g., Internet communication or virtual communication, Internet discourse) to researching communication that is centered around various features and functions of computer technologies, their sociocultural role, etc. The latter area of research, in the broadest sense and in its entirety, is viewed as a particular discourse, i.e., the discourse of information technology (discourse of IT) (more on the discourse of IT see Cukier, et al., 2009; Gev, Sagi, 1996; Lê \& Lê, 2009), whereas focus on particular aspects of language representation (for example, the studies of functional language) of this phenomenon narrows down the scope of research to that of a specific type of this discourse. We interpret the discourse of IT as a "certain communication

The research is financed by the Council for grants of the President of the Russian Federation (project "Conceptual linguistic engineering of professional identity in innovative economy: linguo-cognitive, socio-lexicographic and pragma-axiological modeling of Russian and Western European popular scientific discourse”, № MK-6895.2018.6, project executive - Alexander Y. Bagiyan

Published by Australian International Academic Centre PTY.LTD

Copyright (c) the author(s). This is an open access article under CC BY license (https://creativecommons.org/licenses/by/4.0/) http://dx.doi.org/10.7575/aiac.ijalel.v.7n.7p.52 
structure with domains, in the heart of which there is professional communication" of people involved in the tech industry, "while the periphery is constituted by the communication of non-professionals - people who do not belong to the sphere of information technology and are just language users" (Shiryaeva, et al., 2018).

This article in particular explores professional communication represented in modern-day popular science publications on the topic of information technologies. The choice of this genre - texts of popular science technology magazines - is determined by the fact that popular science bridges purely scientific research results presented in science literature with the sphere of popular cultural discourse, thus allowing discourse producers to preserve scientific tradition and make information accessible to a large number of readers.

The aim of this article is to look at the language of IT on a wider scale so as to establish axiological tendencies and features of the discourse of IT. The authors of the article attempt to take the following steps: a) to validate the study of the language of IT as presented in magazines and journals from the standpoint of axiological linguistics; b) to single out and describe dominating values of the current English discourse of IT (popular science variation).

\section{RESEARCH MOTIVATION AND METHODOLOGY}

There are two factors that preconditioned and motivated this linguistic research, i.e., the analysis of the ways and intentions that people who are professionally involved in the information technology industry have as they communicate various aspects of technologies through magazines and journals. The first factor is the extent to which information technology has spread into most, if not all, spheres of modern society: education, business, healthcare, entertainment, politics, to name just a few. Educators argue that information technology is responsible for the changes in the way people, and students in particular, use language, socialize, share information, and structure communication (Salem, 2013).

Moreover, IT is now the basic technology for storing, processing and spreading data. It provides users with powerful innovative products that people could hardly imagine several decades ago. Constant development of information technology changes the ways we order the reality, the ways we organize work activity, spread knowledge, and it influences the dynamics of value systems to some extent. Thus, it is impossible to overestimate the instrumental role of IT in this digital era.

Another reason for a detailed research of the popular science discourse of IT is that nowadays scientists are aware of an unprecedented number of texts both of oral and written register, all of which are devoted to information technology. Furthermore, special axiological features inherent in this type of discourse generate additional interest to this sphere of professional communication.

When viewed from the standpoint of discourse analysis, information technology reveals not only its technical importance, but also a social one. Critical discourse analysis views language as an important factor that influences and is influenced by social practices. Language has a lot to do with ideology and social power (Fairclough, 1995), and since the discourse of information technology is based on the language, it is fair to say that IT is both a product and an important tool of the modern society.

We also agree with T. Lê and Q. Lê on the following: the results of using information technology are closely connected to social transformations, to social rules and norms, to a wide socio-cultural context. By finding its implementation through social institutions and practices, IT affects the way social institutions exist and function, and thus demonstrates real instrumental power. Moreover, T. Lê and Q. Lê draw our attention to the fact that limited access of certain population groups to technologies may cause social inequality, which also motivates the study of moral issues of the phenomenon (Lê \& Lê, 2009).

At the same time it is of no doubt that dynamic dissemination of IT discourse into all communication practices is followed by changes in personal value systems and leads to changes in both social and communicative behavior, to changing patterns of reality perception (Rokeach, 1973).

\section{AXIOLOGICAL FEATURES OF THE DISCOURSE OF IT}

Due to the fact that modern information technology has interfered with various discourses, professional communication about cutting-edge technical solutions inevitably includes some certain axiological concepts that are integrated into the texts about IT, both intentionally and unintentionally, through various language means. The principal idea behind this research is that values do not only influence a person's communicative behavior and perception of the world but essentially require verbal output. We support E. Benveniste's opinion on the following: "the content of thought receives form when it is uttered, and only thus. It receives form from language and in language which is the mold for all possible expression; it cannot be disassociated from it and it cannot transcend it" (Benveniste, 1992). This natural relationship between language and thought as well as impossibility of complete realization of thought outside language (Benveniste, 1992) leads us to believe that values are conditioned by their verbal and discursive expression and are fully dependent on the language in terms of their functioning and dissemination. Moreover, as a cultural phenomenonlanguage reflects an enormous number of cognitive, culture-specific, social and other features of human existence, which means that language also reflects most important value entities. This is true not only of a value system of a single person, but beliefs and value systems of a nation.

Thus, taking into consideration E. Benveniste's proposition and J. Habermas' suggestion that some social institutes possess enough power to select, form, and disseminate special meanings (Habermas, 1971), we believe it is important to take a closer look at the popular science discourse of information technology and identify language processes that lie behind the formation, verbalization and spreading of particular values.

Due to the existing interdependence of technologies, society and language, it is essential to apply an interdisciplinary 
approach when researching written communication about IT. Linguistics plays as crucial a role in studying values todays as does sociology, the study of culture, and semiotics. Its methods allow scientists to obtain knowledge about the existence of values within a language, both on a level of lexis and semantics, morphology and syntax, as well as to learn about syntagmatic bonds that words verbalizing values establish. Linguistic research also allows finding out about pragmatic and cognitive aspects of verbal representation of the key values in the discourse of IT.

\section{RESULTS AND DISCUSSION}

\section{Criteria for Identification of Values}

In the course of the research we analyzed not only the language embodiment of values in the discourse of IT, but also took into consideration aspects of extra-linguistic origin, thus obtaining a basis for categorizing certain phenomena or artefacts as meaningful and valuable. Due to the fact that axiology always concerns itself with the correlation between "value" and "fact", where values are of subjective nature, and facts - of an objective nature, we feel it is crucial to establish a number of clear criteria for identifying values in the texts, as well as attributing them to those of professional sphere (The Editors of Encyclopaedia Britannica).

According to R.M. Hare, words that verbalize values have both descriptive and prescriptive meanings. The descriptive meaning serves to convey the information about the nominated object or phenomenon. The function of the prescriptive meaning is to recommend: the nominated object is singled out among the alike within the same class of objects. Such language structures, in Hare's opinion, by default have the power to influence people, and their role is to form or strengthen the specific attitude or modality towards the particular object or phenomenon (Hare, 1967).

Another criterion for defining something as having professional value is the frequency of its linguistic realization in the texts about IT. Axiological entities can acquire their linguistic form via the dominant lexeme (the word that names this value in the language) as well as via a lexical-semantic set, both explicitly and implicitly. In our opinion, the fact that people who are professionally involved in the industry constantly turn to explication of the same ideas, notions or artefacts while producing texts indicates their inability to inform, discuss or promote technology without appealing to some certain existential values.

The analysis of texts presented in the top popular science technology magazines in English (Wired, ComputerWorld) led us to believe that the thematic diversity of the articles in these magazines does not suggest verbalization of an equally diverse set of values. On the contrary, it is possible to say that IT texts contain some certain recurrent values. Their presence in the written professional communication is determined by the axiological picture of the world (the combination of values) that is specific for this particular profession as well as for the nation, rather than by the author's personal system of values.

\section{Key Values of the Popular Science Discourse of IT}

\section{The value of data}

The conducted study revealed that one of the fundamental values of the modern English discourse of IT is data. The sphere of IT interprets "data" as information stored on or processed by a computer. Data can take many forms: text documents, images, audio files, software, etc. Since data todays is the basis for commercial success, political impact, cultural exchange, social interaction and many other processes and phenomena, the value of data is verbalized in a vast number of texts, the specifics of storing, processing and using data is a widely discussed topic in the society. The following extract demonstrates the value:

(1) "There's a whole lot of data carried in your face: your age, your gender, even your emotional state at the time. And, those are things that could be useful outside of simply authentication" (Aley as cited by Mearian, 2018).

We can find an explicit assessment of the phenomenon of data in the example above: the addresser considers it useful for a number of reasons. Firstly, the combination of biological information contained in a person's face has more pragmatic potential today than ever before. Modern day technology uses visual information in completely new ways - from authentication on mobile devices, computers and other gadgets to the improvement of security systems:

(2) The company's NeoFace Watch integrates face-matching technology with video surveillance to check individuals against known photographic watch lists and generate real-time alerts when matches are found (Mearian, 2018).

So, as we can see, one of the examples of using data is for security measures - many believe that identifying a face in the crowd and instantly alerting the security service in real time is a step to creating a safer environment in public places. However, it is important to note that the value of data cannot be viewed separately from other values that it is connected to.

\section{The value of security and privacy}

As entities of psychological and cognitive origin, values do not function as isolated items but rather complement and influence each other. This idea fits with the theory of an American psychologist C.W. Graves (Emergent Cyclical Levels of Existence Theory), according to which every new emerging system of values that appears as a result of people's adaptation to a new environment is inevitably linked to the previous system and cannot exist independently (Graves, 2004).

In a similar way data is connected to at least two other values: those of security and privacy. The concept of security has always belonged to existential values of mankind (it is verbalized in Text fragment 2 as well), while the importance of privacy has become more evident in the recent years as the result of rapid technological advancements. Because of extensive data collection which is carried out by numerous services daily, people are now facing unprecedented vulnerability in terms of safety and their right to privacy. This tendency is fully reflected in the texts of popular science technology magazines: the values of security and privacy 
are part of the journals' rhetoric because addressers want to discuss these values in their own right, or they touch upon these entities indirectly - in the context of information technology news and trends.

A vivid example of how language representation of security and privacy contributes to the discourse of IT is the overwhelming attention that has been paid both by mass media and professional technology publications to the recent controversy caused by the technical giant Facebook. In April 2018 Facebook CEO M. Zuckerberg gave testimony on the company's data-privacy policies in the US Senate, and his speech extended the on-going discussion, which was and is propelled via texts, even further:

(3) We face a number of important issues around privacy, safety and democracy...

It's not enough to just connect people. We have to make sure that those connections are positive. It's not enough to just give people a voice. We need to make sure that people aren't using it to harm other people or to spread misinformation. And it's not enough to just give people control over their information. We need to make sure that the developers they share it with protect their information, too.

Second, to make sure no other app developers out there are misusing data, we're now investigating every single app that had access to a large amount of information in the past. (Zuckerberg as cited by Washington Post, 2018).

The addresser of Fragment 3 focuses on explication of the current situation in the sphere of IT (We face a number of important issues) as well as clearly states the importance of personal data (protect information; make sure that people aren't using it to harm other people or to spread misinformation); the text also suggests methods of fighting unethical or illegal use of data (to protect; to control; to ban). The use of parallel constructions along with the opposition created by the phrases it's not enough. - we have to...; it's not enough... - we need to... creates the sense of necessity to take action, and actually puts forward specific axiological meanings ideas or concepts that are valuable for the addresser and possibly for the addressee.

All of these language aspects indicate the high value that both the society and people involved in the industry professionally attribute to the right of privacy and the ability to live safely both in the digital and real life environment. Moreover, it is fair to say that the language plays an instrumental role in giving the values their form and resources to spread and influence some certain areas of users' reality.

\section{The value of evolution}

The analysis of the texts about information technology revealed that staying up-to-date is another important feature both for the industry and for the people that follow it. Evolution is an integral part of the world of technology and the value that is widely represented in the popular science technology magazines. Evolution is the only way for this industry to exist and for the market to grow, so the language that describes the latest developments in various fields of technology serves as one of the most efficient marketing tools. As a result, current popular science discourse of IT includes many linguistic markers that represent the value of evolution. Our findings suggest that on the level of the language this value is verbalized through the following lexical set: evolution (primary way of nominating the value in the texts), development, advancement, resilience, update; to evolve, to develop, to adapt. Let us consider the following fragment which features the value of evolution:

(4) Marketers know that staying in the loop is make or break for their careers. Keeping up with trends is completely in the job description but any marketing professional knows just how difficult that can be. As it seems that Google launches a new update daily or a new social platform reigns supreme, staying up to date with the latest technological update is a challenge.

One of the best ways to remain up-to-date with the latest in tech is to keep up with some key tech sources. We've listed the top ten tech magazines to help keep you aware of the latest and greatest. (Landers, 2017).

The addresser of Fragment 4 uses various language means to stress the importance of staying up-to-date. Firstly, by using intensifiers completely and reign supreme the author of the text expresses an additional level of value and employs these words as tools "to convince the reader to the validity of his point of view" (Benzinger, 1971), according to which it is both crucial and challenging for the professionals to evolve with the technology industry. Secondly, the value of evolution is verbalized here more than once, the addresser repeats the idea of how changeable the companies and their products are: staying in the loop, keeping up with trends, Google launches a new update daily, a new social platform reigns supreme, staying up to date with the latest technological update. The linguistic form that the addresser gives to the value evolution in this text fragment is both expressive and convincing; it contributes to overall understanding of how things run in the sphere of information technology as well as brings forward the importance of specialist publications and practical use of magazines: We've listed the top ten tech magazines to help keep you aware of the latest and greatest.

Let us take a look at another example of how the value evolution is represented in the text, and this time it concerns the product itself, rather than people professionally employed in the sphere:

(5) Nathan Schneider, a professor of media studies at the University of Colorado, said it best: "Email is the most resilient social network on the internet. and the thing that allows it to adapt is that it's an open protocol, and people build apps on top of it, and we evolve how we use it." (Elgan, 2018).

In Fragment 5 the addresser cites a university professor in order to better support his opinion regarding emails and their on-going popularity and usability. As a product that appeared long before social networks, electronic mail keeps evolving and retaining users despite the plethora of other ways that allow people to connect and exchange files. The reason why emails are still in the game, according to the author of the fragment, is because this service keeps changing with the time: Email is the most resilient social network on the internet; ... the thing that allows it to adapt is open protocol.... The words resilient and adapt are a way of conveying the idea of constant development which is key to success. 
Moreover, it is not only the technology that changes, but also the consumers who have been using it for a while: people build apps on top of it, and we evolve how we use it.

Thus, continuous development from old to new, from one function to multiple functions, from convenient to more convenient, etc., is one of the most important factors that define the industry of information technology today and shape the linguistic form of the corresponding value of evolution.

\section{The value of domination}

Another value featured in the texts about IT is domination. As the research shows, popular science texts that represent the industry of information technology today draw the readers' attention not only to the changes in the way we perceive and use the information technology, but also raise awareness of the companies and technologies that are global leaders in the field. These are highly efficient, reliable products, services and software which help people, among other things, to be a part of a global network and experience technologies that are most in demand. Linguistically, the value of domination is often expressed through the following lexis: domination, growth, increase, size, as well as via the corresponding verbs: to dominate, to grow, to increase.

However, it is important to distinguish the difference between the values evolution and domination in cases when the latter is verbalized via the word "growth". While evolution reflects the need of information technology products to improve and adapt in order to be valid in the conditions of the extremely competitive market, the value of domination suggests control that is mostly reflected in numbers and statistics. Although evolution as a process can suggest growth as part of it, we still believe that identifying domination as a value in its own right is justified because of the attention that this particular value entity gets in the current discourse of information technology and, of course, due to its extensive verbalization in the texts of technology magazines.

Let us examine the following text fragment for the linguistic representation of the value domination:

(6) In fact, email has been, is and will continue to be superior to newer communications media. One reason is sheer size (enhanced network effect).

Facebook is considered the dominant social network because, as of Q4 last year, it had 2.2 billion monthly active users.

Impressive, but not as impressive as the 3.8 billion email users estimated by market research firm Radicati Group. And email users send hundreds of billions of emails every day.

Google, which now has 1.2 billion email users, according to a company spokesperson, rules the email universe. Google's Gmail and Inbox services are also both the most innovative and best-supported platforms (often through Chrome extensions) (Elgan, 2018).

In the text fragment above emails are assessed as a superior service mostly because of the number of users loyal to it: One reason is sheer size. As a way of proving his point, the addresser of the text compares the two most used services - emails and Facebook. While explicitly verbalizing the value of domination, the author of the text also offers information that is supposed to affect and convince the reader of the fact that the number of people using this particular technology defines its success and superiority: Facebook is considered the dominant social network... it had 2.2 billion monthly active users. vs. ...3.8 billion email users;... email users send hundreds of billions of emails every day. According to the addresser, being dominant means being in control and in power: Google, which now has 1.2 billion email users ... rules the email universe.

Thus, the linguistic analysis of the popular science texts shows that it is crucial for the technology magazines both to focus on the products and services which are in demand and to establish an ever changing standard (in terms of size) that they can measure the popularity of other products against. Domination as a value characteristic of the information technology sphere is verbalized besides the above mentioned lexical set through numbers that serve to demonstrate and inform as well as influence and shape the opinion of the addressee.

\section{CONCLUSION}

Taking everything abovementioned into consideration it is possible to say that the modern day discourse of information technology as represented in the popular science technology magazines is an axiologically rich sphere of communication. As the result of the conducted research we have been able to establish the necessity to explore the language of IT magazines within the framework of axiological linguistics. The data that we have obtained suggest that the texts of the information technology magazines not only convey the factual information about trends and products, companies and inventions, but also explicitly and implicitly verbalize a number of values which are characteristic of the IT industry today. A closer look into the depth of the meanings which lie beyond the general understanding of the identified values suggests that these entities dominate the current English discourse of IT in terms of communication outcome, context layout, cognitive potential and cultural patterns that they create.

The values of data, security, privacy, evolution and domination are among the most important linguistically embodied concepts which define much of current information technology-related reality. Of course, these are not the only values that belong to the axiological system of IT professionals, but they are definitely timely and relevant. As the research indicated, the language that conveys the identified values is very diverse and employs different means of expressing the ideas connected to the value system of the professional IT community, such as linguistic markers, stylistic devices, expressive means, etc. These ideas are important for the addressers and are intended to become important for the addressees. Thus, a language plays a crucial role in forming, changing and spreading values; it reflects the latest developments of the society and the industry of information technology, which makes it a significant and interesting area for study. 


\section{REFERENCES}

Benveniste E. (1992). Categories of Thought and Language. In G.H. Singh \& P. Bernard (Eds.), Ideas, Words And Things: French Writings In Semiology. (pp. 93-104). New Delhi: Orient Longman Ltd.

Benzinger E.M. (1971). Intensifiers in Current English. A dissertation presented to the graduate council of the University of Florida in partial fulfillment of the requirements for the degree of doctor of philosophy. University of Florida. [Online] Available: https://archive.org/ stream/intensifiersincu00benz/intensifiersincu00benz djvu.txt (February 21, 2018).

Cukier W., Ngwenyama O., Bauer R. et al. (2009). A Critical Analysis of Media Discourse on Information Technology: Preliminary Results of a Proposed Method for Critical Discourse Analysis. In D. Avison, G. Fitzgerald, P. Powell (Eds.), Information Systems Research Vol. 19. (pp. 175-196). Blackwell Publishing Ltd. https://doi. org/10.1111/j.1365-2575.2008.00296.x.

Elgan M. (2018). Why email is the best social network. [Online] Available: https://www.computerworld.com/ article/3267698/email/why-email-is-the-best-socialnetwork.html (April 1, 2018).

Fairclough N. (1995). Critical Discourse Analysis (1 ${ }^{\text {st }}$ edition). London: Longman.

Gev Y., Sagi I. (1996). Information Technology Discourse as a Catalyst for Cultural Change. In: Y.J. Katz, D. Millin, B. Offir (Eds.) The Impact of Information Technology. IFIP Advances in Information and Communication Technology. Springer, Boston, MA.

Graves C.W. (2004). Levels of Human Existence. Lee W.R., Cowan C., Todorovic N. (Eds.), Santa Barbara, CA: ECLET Publishing.

Habermas J. (1971). Knowledge and Human Interests. J. J. Shapiro (trans.), Boston: Beacon.

Hare R.M. (1967). The language of morals. London: Oxford UP.
Landers J.S. (2017). The Top Ten Technology Magazines [Online] Available: https://www.sixstories.com/2017/07/ the-top-ten-technology-magazines (January 6, 2018).

Lê T., Lê Q. (2009). Information Technology: A Critical Discourse Analysis Perspective. In D.L. Pullen, C. Gitsaki, M. Baguley (Eds.), Technoliteracy, Discourse, and Social Practice: Frameworks and Applications in the Digital Age. Information Science Reference, the USA. (pp. 80-86). https://doi.org/10.4018/978-1-60566-842$0 . \operatorname{ch} 005$.

Mearian L. (2018). Facial recognition tech moves from smartphones to the boardroom [Online] Available: https:// www.computerworld.com/article/3267488/emerging-technology/facial-recognition-tech-moves-fromsmartphones-to-the-boardroom.html (April 2, 2018).

Rokeach M. (1973). The Nature of Human Values. New York, The Free Press.

Salem A.A.M.S. (2013). The impact of Technology (BBM and WhatsApp Applications) on English Linguistics in Kuwait. In J.I. Liontas, Z. Golebiowski, J. Mukundan (Eds.), International Journal of Applied Linguistics \& English Literature. Vol. 2 No. 4; July 2013. (pp. 64-69). Australian International Academic Centre PTY. LTD. http://dx.doi.org/10.7575/aiac.ijalel.v.2n.4p.64.

Shiryaeva T. et al. (2018). A Theory-driven Framework for the Study of Language in Business. XLinguae. Vol. 11 Issue 1 (pp. 82-90). [Online] Available: http://www.xlinguae.eu/files/XLinguae1_2018_8.pdf (April 10, 2018) https://doi.org/10.18355/XL.2018.11.01.08.

The Editors of Encyclopaedia Britannica. Axiology [Online] Available: https:/www.britannica.com/topic/axiology (April 5, 2018).

The Washington Post (2018). Transcript of Mark Zuckerberg's Senate hearing [Online] Available: https://www. washingtonpost.com/news/the-switch/wp/2018/04/10/ transcript-of-mark-zuckerbergs-senate-hearing/?noredirect $=$ on (April 12, 2018). 